University of New Hampshire

University of New Hampshire Scholars' Repository

$1-2004$

\title{
Explanations for the Decline in Child Sexual Abuse Cases.
}

\author{
David Finkelhor \\ University of New Hampshire - Main Campus, David.Finkelhor@unh.edu
}

Lisa M. Jones

University of New Hampshire - Main Campus, lisa.jones@unh.edu

Follow this and additional works at: https://scholars.unh.edu/ccrc

Part of the Psychology Commons, and the Sociology Commons

\section{Recommended Citation}

Finkelhor, David and Jones, Lisa. Explanations for the decline in child sexual abuse. Juvenile Justice Bulletin - NCJ199298 (pgs. 1-12). Washington, DC: US Government Printing Office.

This Article is brought to you for free and open access by the Research Institutes, Centers and Programs at University of New Hampshire Scholars' Repository. It has been accepted for inclusion in Crimes Against Children Research Center by an authorized administrator of University of New Hampshire Scholars' Repository. For more information, please contact Scholarly.Communication@unh.edu. 


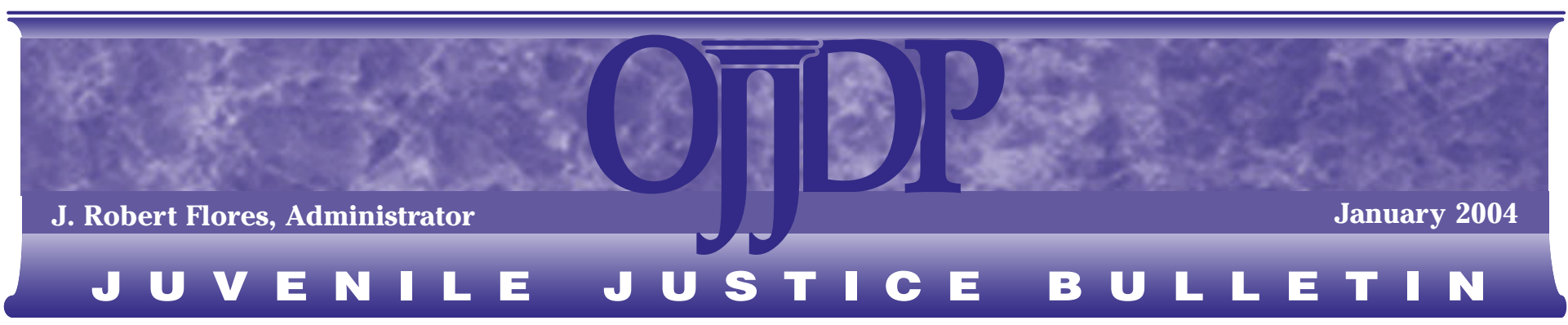

\section{Explanations for the Decline in Child Sexual Abuse Cases}

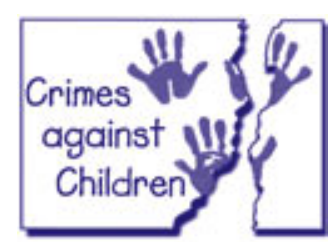

\section{David Finkelhor and Lisa M. Jones}

The Office of Juvenile Justice and Delinquency Prevention (OJJDP) is committed to improving the justice system's response to crimes against children. OJJDP recognizes that children are at increased risk for crime victimization. Not only are children the victims of many of the same crimes that victimize adults, they are subject to other crimes, like child abuse and neglect, that are specific to childhood. The impact of these crimes on young victims can be devastating, and the violent or sexual victimization of children can often lead to an intergenerational cycle of violence and abuse. The purpose of OJJDP's Crimes Against Children Series is to improve and expand the nation's efforts to better serve child victims by presenting the latest information about child victimization, including analyses of crime victimization statistics, studies of child victims and their special needs, and descriptions of programs and approaches that address these needs.

The number of sexual abuse cases substantiated by child protective service (CPS) agencies dropped a remarkable 40 percent between 1992 and 2000, from an estimated 150,000 cases to 89,500 cases, but professional opinion is divided about why (Jones and Finkelhor, 2001; Jones, Finkelhor, and Kopiec, 2001). It is possible that the incidence of sexual abuse has declined as a result of two decades of prevention, treatment, and aggressive criminal justice activity. It is also possible that there has been no real decline, and that the apparent decline is explained by a drop in the number of cases being identified and reported or by changes in practices of child protection agencies.
Identifying the source or sources of the decline in the number of substantiated sexual abuse cases is important. The possibility that a real decline occurred is heartening and could point the way to more effective strategies for preventing all kinds of child maltreatment. On the other hand, if the decline is due solely to decreased reporting or changes in CPS procedures, it could mean that more children are failing to get the help and services they need.

This Bulletin explores the strengths and weaknesses of six possible explanations for the decline by using data from a number of different sources (see page 3): aggregate data from the National Child

\section{A Message From OJJDP}

The decline in sexual abuse cases, as reported by child protective service agencies, could be an encouraging development if future analysis and research establish its significance. The uncertainty about the meaning of this trend, however, underscores how much remains to be accomplished in terms of drawing lessons from past experience to determine future policy. Clearly, a trend of this magnitude merits further inquiry and analysis.

For example, it would be useful to know whether policies of more aggressive prosecution, incarceration, and treatment have played a role. If so, what will be the impact when many of the large group of sexual abuse offenders placed in custody in recent years are released from their sentences? From another perspective, have efforts to educate children and to identify and treat juvenile sex offenders had the effect of reducing the number of victims and perpetrators?

This Bulletin reviews six plausible explanations for the decline in sexual abuse cases in light of available data. While acknowledging the likelihood that multiple factors are involved, the authors find evidence of a significant decline in child sexual abuse.

Federal, state, and local agencies should collaborate on a research agenda that will cast light on the meaning of this trend. 
Abuse and Neglect Data System (NCANDS); detailed child protective service data from Illinois, Minnesota, Oregon, and Pennsylvania; and self-report data from the National Crime Victimization Survey (NCVS) and from schoolchildren in Minnesota. It provides substantially more evidence about the decline than was available in a previous Bulletin on the same topic, The Decline in Child Sexual Abuse Cases (Jones and Finkelhor, 2001).

\section{Key Findings}

- Detailed data provided by four state CPS agencies offered little evidence that the decline was due either to more conservative judgment by CPS about the types of sexual abuse cases they would investigate or substantiate or to increasing reluctance by CPS to become involved in cases in which the perpetrator is not a primary caregiver.

- There also was no strong evidence that the decline was largely due to a diminishing reservoir of older, ongoing cases available for new disclosures.

- There was some evidence that the sexual abuse decline in one state could be partly explained by changes in CPS procedures and data collection methods. According to national data, however, this explanation does not successfully account for the declines seen in the majority of states.

- There was mixed evidence that reporting of sexual abuse to CPS declined because of a "backlash," that is, a greater public and professional skepticism about reports of sexual abuse.

- Evidence from a number of different sources, including NCVS data showing a 56 -percent decline in self-reported sexual assault against juveniles, is consistent with a real decline in sexual abuse.

- Finally, additional studies and improved data are needed to make crucially important decisions for public policy based on the factors that are most responsible for the decline.

\section{Evidence for the Decline}

Yearly estimates of substantiated sexual abuse from 1992 to 2000 were calculated from CPS administrative data collected by NCANDS. The number of states that submitted data to this system each year varied from 43 to 49 , making published totals difficult to compare across years. To arrive at more comparable numbers, sexual abuse totals were extrapolated to account for the population of all 50 states and the District of Columbia as estimated annually by the U.S. Census. These extrapolated totals show that the number of substantiated sexual abuse cases reached a peak of approximately 149,800 in 1992 , followed by declines of 2 to 11 percent each year through 2000, the last year for which data are available (see figure 1). In 2000, estimated cases of sexual abuse reached a low of approximately 89,355 , for a total decline of 40 percent in identified sexual abuse cases over the 8-year period. The trend is not universal, but it has occurred in the majority of states. Of 49 states, 39 experienced a total decline of 30 percent or more in substantiated cases of sexual abuse from their peak year to 2000, and 19 of these states saw declines of more than 50 percent in their sexual abuse caseloads.

The decline in sexual abuse does not appear to be just an extension of a general declining trend in overall child maltreatment or of some other demographic factor. According to estimates based on the NCANDS data, the decline in sexual abuse appears to account for a large part of the 15-percent decline in child maltreatment. Neglect cases have fluctuated during the 1990 s with no overall decline while physical abuse has declined 30 percent since a peak in 1995. The decline in physical abuse is significant, but it is smaller and more recent than the decline in sexual abuse. In fact, the largest proportion of the decline in physical abuse (15 percent) occurred between 1998 and 1999, whereas the more gradual 40-percent decline for sexual abuse occurred over an 8-year period.

\section{Explanations for the Decline}

As part of their earlier research on this topic, the authors conducted a survey of state child protection administrators to gather hypotheses and evidence about the decline in sexual abuse (Jones, Finkelhor, and Kopiec, 2001). Although the administrators expressed many ideas about the decline, six explanations were offered frequently and backed by some anecdotal support:

\section{- Increasing conservatism within CPS.} In this view, sexual abuse cases were declining in state caseloads because CPS was adopting more conservative standards regarding "questionable" cases (e.g., allegations arising in divorces and custody disputes) or cases with weak initial evidence.

- Exclusion of cases that do not involve caretakers. In this view, CPS was increasingly excluding from its jurisdiction sexual abuse cases in which the perpetrator was not a primary caregiver.

$\checkmark$ Changes in CPS data collection methods or definitions. In this view, the decline was due to changes in the way CPS tabulated or counted its cases, such as changing from a three-tiered

\section{Figure 1: Estimated Number of Substantiated Cases of Sexual Abuse in the United States, 1990-2000}

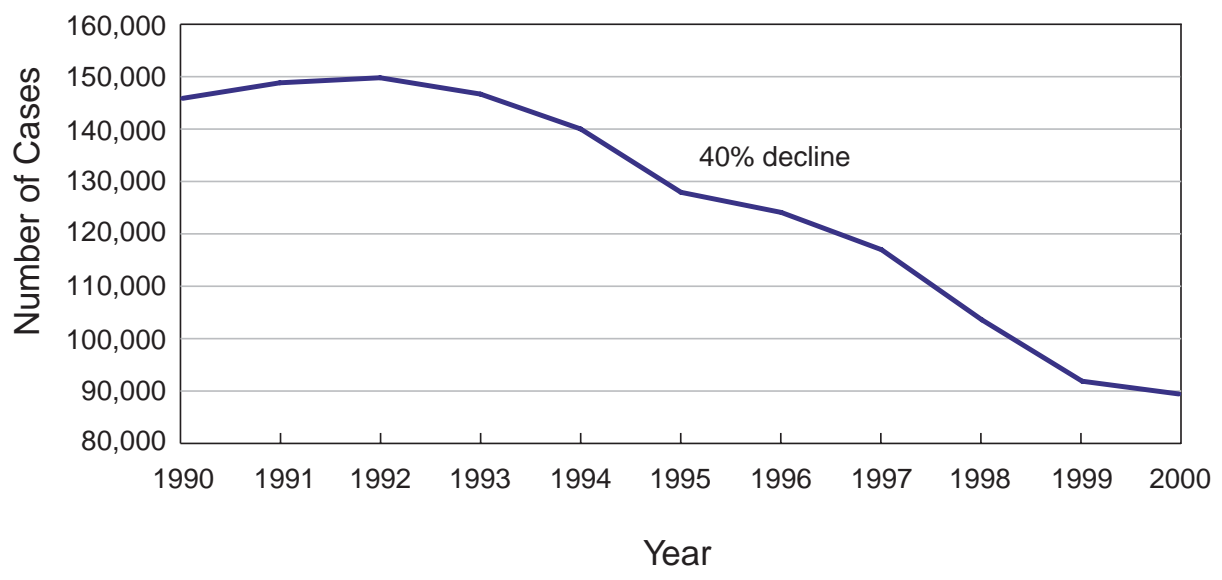

Source: Authors' analyses of data from 1990-2000 National Child Abuse and Neglect Data System (NCANDS) reports (U.S. Department of Health and Human Services, 1992-2002). 


\section{Data Sources on Sexual Abuse Trends}

National Child Abuse and Neglect Data System (NCANDS). NCANDS, organized by the U.S. Department of Health and Human Services' Children's Bureau, collects information from state child welfare agencies on a number of variables related to child maltreatment. Data collection through this system began in 1990. Although a growing number of states submit case-level data to NCANDS, aggregate data from the Summary Data Component (SDC) were used to calculate national sexual abuse trends from 1990 through 2000. The SDC provides annual estimates of child maltreatment cases substantiated by child protective services. These data have many limitations, including the fact that states vary considerably in how they define maltreatment and how they investigate and count cases.

State Child Protective Service Data. To examine sexual abuse trends in more detail, the authors also examined state CPS data from Illinois, Minnesota, Oregon, and Pennsylvania. These states showed large declines in substantiated sexual abuse and were among the few states for which consistent and extensive case-level CPS data were available from the early 1990s through 1999. The data provided by these states allowed an examination of trends in sexual abuse investigations by the age of the victim, the type of abuse, the perpetrator's relationship to the victim, the age of the perpetrator, and the investigation outcome, among other factors.

National Crime Victimization Survey (NCVS). NCVS is conducted annually by the U.S. Department of Commerce's Bureau of the Census on behalf of the U.S. Department of Justice's Bureau of Justice Statistics. Approximately 55,000 U.S. households with a total of 100,000 individuals ages 12 and older are surveyed each year. The survey collects information about the characteristics of victimizations, including victim and perpetrator demographics, the incident location, and a description of the incident.

Minnesota Student Survey. The Minnesota Student Survey is a voluntary, anonymous, self-administered questionnaire that asks students about a range of experiences including substance use, sexual behavior, and school climate. Two survey questions ask about sexual abuse victimization. The survey has been administered to 6th, 9th, and 12th grade students in Minnesota five times: in 1989, 1992, 1995, 1998, and 2001. Approximately 90-99 percent of Minnesota's school districts have participated in the survey each year, involving more than 100,000 students. For trend analyses, data are limited to the approximately 69 percent of Minnesota's school districts that participated in the survey in all 5 years. A weighting procedure was used to adjust for differences in student participation rates across districts. ${ }^{1}$

1 For more information about the Minnesota Student Survey's methodology, see Harrison, Fulkerson, and Beebe (1997), or Minnesota Department of Children, Families \& Learning (2001).

classification system (substantiated/ indicated/unsubstantiated) to a two-tiered system (substantiated/ unsubstantiated).

Less reporting to CPS due to a sexual abuse backlash. In this view, negative publicity about sexual abuse cases and the potential liability of professionals who report suspected abuse made the public and professionals more reluctant to report sexual abuse.

- A diminishing reservoir of older cases. In this view, there had been a reduction in the supply of older but previously undisclosed cases available for new disclosures but no true decline in new cases.

- A real decline in the incidence of sexual abuse. In this view, there was a reduction in the number of children actually being abused as a result of increased prevention efforts, more prosecution and incarceration of offenders, or other social or cultural changes. ${ }^{1}$

\footnotetext{
1 Specific mechanisms for a real decline will be explored in subsequent research.
}

\section{Explanations and the Evidence}

The following sections review evidence that might be marshaled to support each of the six possible explanations for the reduction in sexual abuse cases. Evidence was drawn from a variety of sources but especially from the four states with extensive CPS data.

\section{Increasing Conservatism Within CPS}

One very plausible explanation of the decline in substantiated sexual abuse cases is that child protection agencies have become more conservative regarding the cases they investigate or substantiate. This may reflect a better knowledge base, a reaction to criticism about overzealous investigations, caution in anticipation of legal retaliation, an effort to triage cases brought about by limited resources, or a concern about unnecessarily stigmatizing people by subjecting them to investigations based on questionable information. An obvious place to look for increasing skepticism about questionable cases would be in the substantiation rate. That is, if CPS workers were applying more conservative standards and confirming less sexual abuse, there might be a greater drop in substantiated than in reported or investigated cases.

However, there is not much evidence for such a pattern. For example, in Illinois, substantiations and investigations declined in tandem (see figure 2). Similar patterns were identified in Minnesota and Pennsylvania. Nationwide, evidence provided by the 50 -state survey shows that the substantiation rate for all types of maltreatment remained constant at 33 percent from 1994 through 1999 (Peddle and Wang, 2001).

If increasing conservatism among CPS staff explained the decline, then a greater number of conservative judgments would also be expected in certain kinds of potentially questionable cases. In recent years, skeptics concerned about unnecessary investigations have particularly targeted certain allegations, such as those arising in divorce and custody disputes; those involving very young children, whose testimony is often deemed unreliable; and those involving less intrusive forms 


\section{Figure 2: Illinois Trends in Sexual Abuse Investigation and Substantiation, 1990-99}

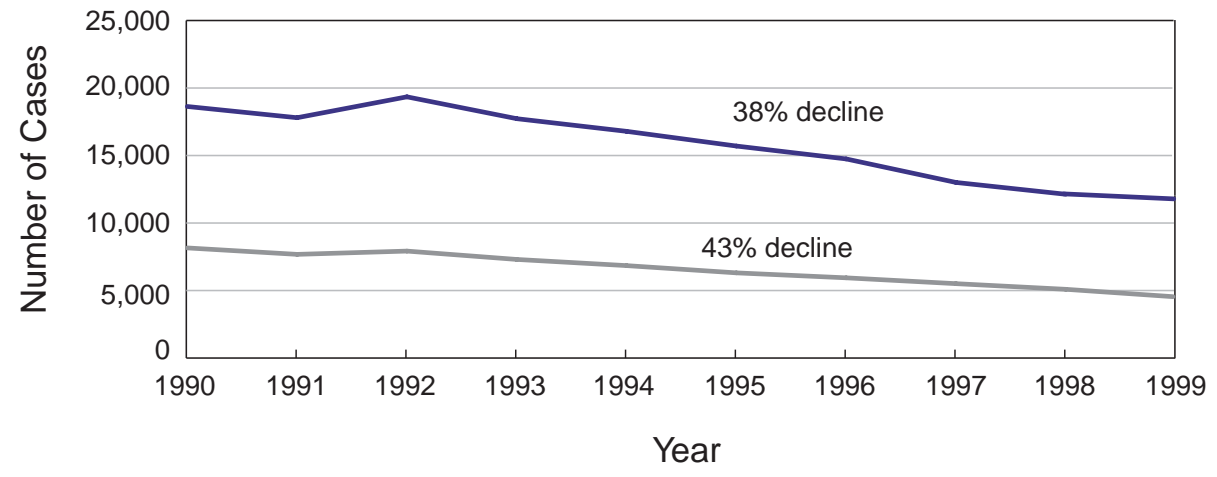

- Investigated

- Substantiated

Source: Authors' analyses of unpublished data provided by the Illinois Department of Child and Family Services.

\section{Figure 3: Pennsylvania Trends in Sexual Abuse Cases, by Living Situation of Victim at Time of Report}

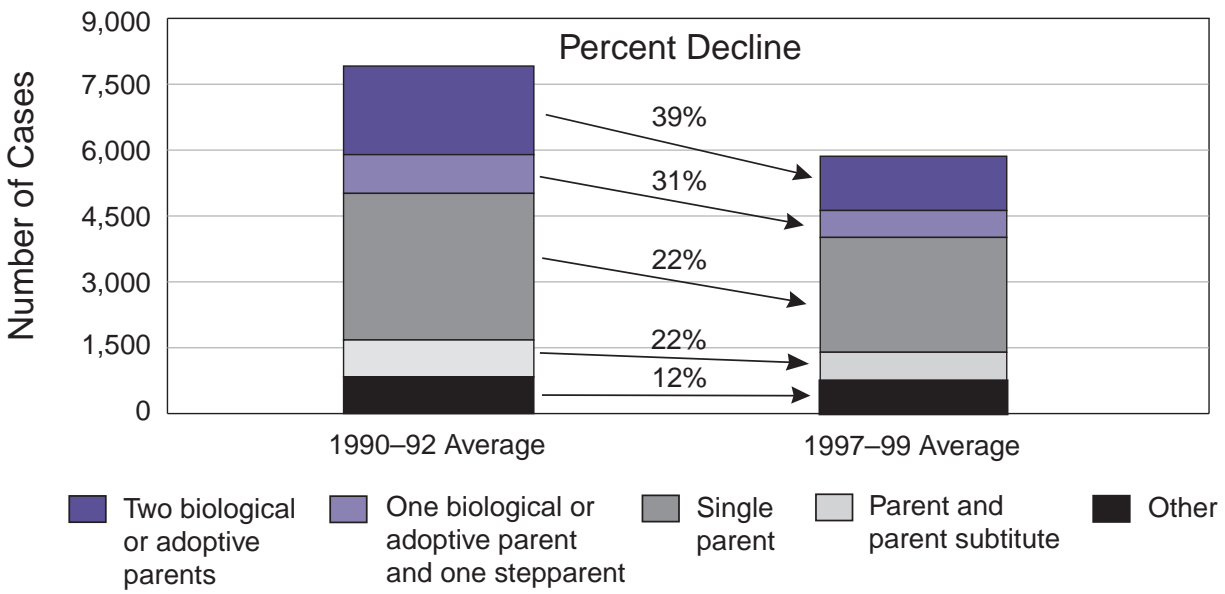

Source: Authors' analyses of unpublished data provided by the Pennsylvania Office of Children, Youth, and Families.

of sexual contact. If increasing conservatism about questionable cases were an important factor in the decline of sexual abuse, it would be reasonable to predict a differentially greater decline in these types of cases. At the same time, a less pronounced decline might be seen in cases involving more credible evidence, such as medical evidence or a perpetrator confession, and more serious kinds of contact, such as penetration.

Trend data for cases involving questionable allegations are presented in figures
3-6. Unfortunately, case reports in the available states do not indicate whether they were preceded by a custody dispute. In Pennsylvania, however, case reports do indicate the family structure of the child's household. Cases in which a custody dispute precedes a sexual abuse allegation are less common in families where two biological parents are present at the time of the allegation. (Sometimes a custody dispute follows the allegation of sexual abuse in an intact family, but in these cases, CPS would be less likely to assume that the sexual abuse allegation was an attempt to manipulate an already existing custody conflict.) Sexual abuse allegations arising in previously existing custody disputes would be expected more often when children reside in single-parent or stepparent households than when they reside in households with two biological parents. A greater decline could be expected in such cases if CPS became increasingly skeptical about them. Trends in Pennsylvania do not follow that pattern. In fact, figure 3 shows that the largest declines in Pennsylvania have occurred in allegations coming from families with two biological or adoptive parents, instead of families with single parents or stepparents.

Trend data are somewhat more supportive of the hypothesis that increasing conservatism among CPS staff is affecting the decline in substantiated cases of sexual abuse for cases involving younger children. In Illinois, Minnesota, and Pennsylvania, the decline was most pronounced for cases involving children younger than 6 . For example, figure 4 shows a 57 percent decline in Illinois cases with child victims ages $0-2$, compared with an average 26-percent decline across other age groups. However, the decline has not been limited to cases with victims ages $0-2$; it has occurred across all age groups, with a higher rate of decline for cases involving very young victims. Because the very young make up a small portion of all victims of sexual abuse, even fairly big declines for this age group are not enough to account fully for the overall decline in sexual abuse cases.

Where there is other information from states on the quality or seriousness of the allegation or evidence, it generally does not support the hypothesis that there were especially dramatic declines in questionable cases. Case records in Pennsylvania record the presence of medical evidence or perpetrators' confessions. As shown in figure 5, the decline in Pennsylvania cases with such strong evidence has been as great, if not greater, than the decline in weaker cases. Illinois records the presence of sexually transmitted diseases (STDs) and allegations of penetration. Here again, the declines are substantial in cases in both categories, and they are lowest in the category of exploitation alone, which might contain some of the least serious cases and those with the weakest evidence (see figure 6).

The finding that the decline in sexual abuse cases with stronger evidence was 
comparable to that of cases without such evidence is far from fatal to the "increasing conservatism" argument. For example, large declines in STDs may be due to the decline in STDs in the general population (Centers for Disease Control and Prevention, 2000). Standards of medical evidence may also have become more conservative (Carole Jenny, Brown University, personal communication, May 14, 1997), and perpetrators may be newly emboldened by defense attorneys not to confess. But the data do not give strong or consistent evidence that the exclusion of questionable cases-those that involve controversial allegations or weaker evidence-is a major factor in the decline in sexual abuse cases.

\section{Exclusion of Cases That Do Not Involve Caretakers}

According to child protection officials, in recent years, some states have dealt with burgeoning caseloads and declining resources by narrowing the scope of child welfare responsibilities (Jones, Finkelhor, and Kopiec, 2001). Because the traditional and statutory responsibilities of child protection have concerned threats to children's well-being at the hands of caretakers, some state agencies have increasingly excluded cases that involve allegations of abuse by noncaretakers, including nonrelatives, distant relatives, and juvenile offenders. Compared with other kinds of maltreatment, sexual abuse cases have typically involved more allegations of offenses by noncaretakers. If a rise of such exclusionary policies were responsible for the decline in substantiated cases of sexual abuse, greater declines could be expected in cases involving perpetrators who are not caretakers.

The available data from the states examined for this Bulletin show some evidence of a differential decline for cases that involve noncaretakers and juvenile perpetrators, but this evidence was not strong. There may have been some differential decline in cases involving young perpetrators. Trend data for Pennsylvania showed a larger decline in cases with perpetrators ages 12-17 than in cases with older perpetrators (see figure 7). However, the number of teen perpetrators was already small, and the larger percentage of decline did not account for much of the overall decline. There was no evidence for the exclusion of cases with noncaretaker perpetrators in the three states where these data were available. For example, in Illinois, the decline was most dramatic for cases involving parental perpetrators, the

Figure 4: Illinois Trends in Sexual Abuse Cases, by Age of Victim at Time of Report

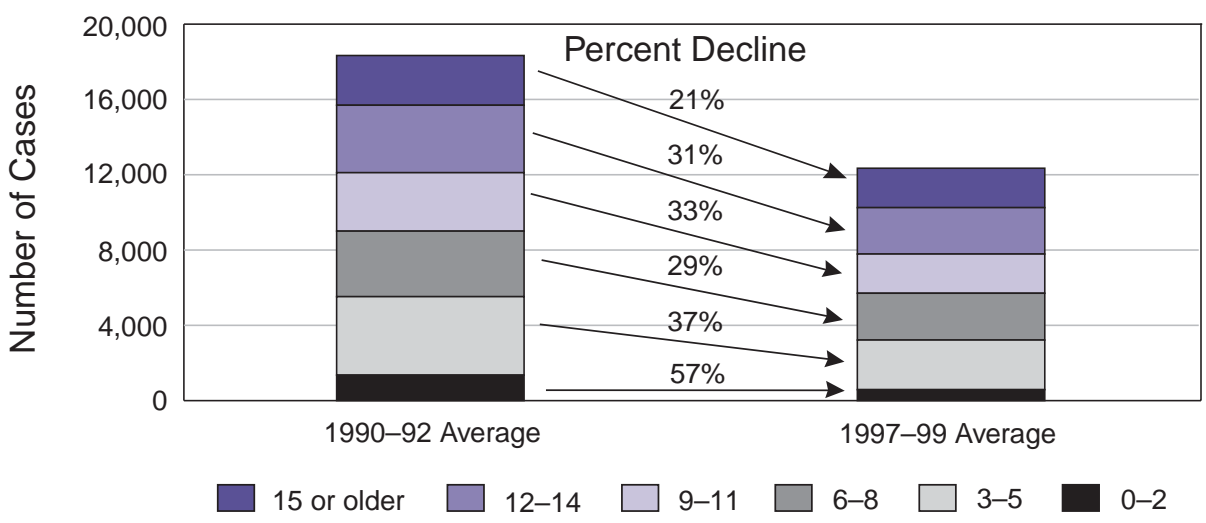

Source: Authors' analyses of unpublished data provided by the Illinois Department of Child and Family Services.

Figure 5: Pennsylvania Trends in Indicated Cases of Sexual Abuse, by Type of Evidence

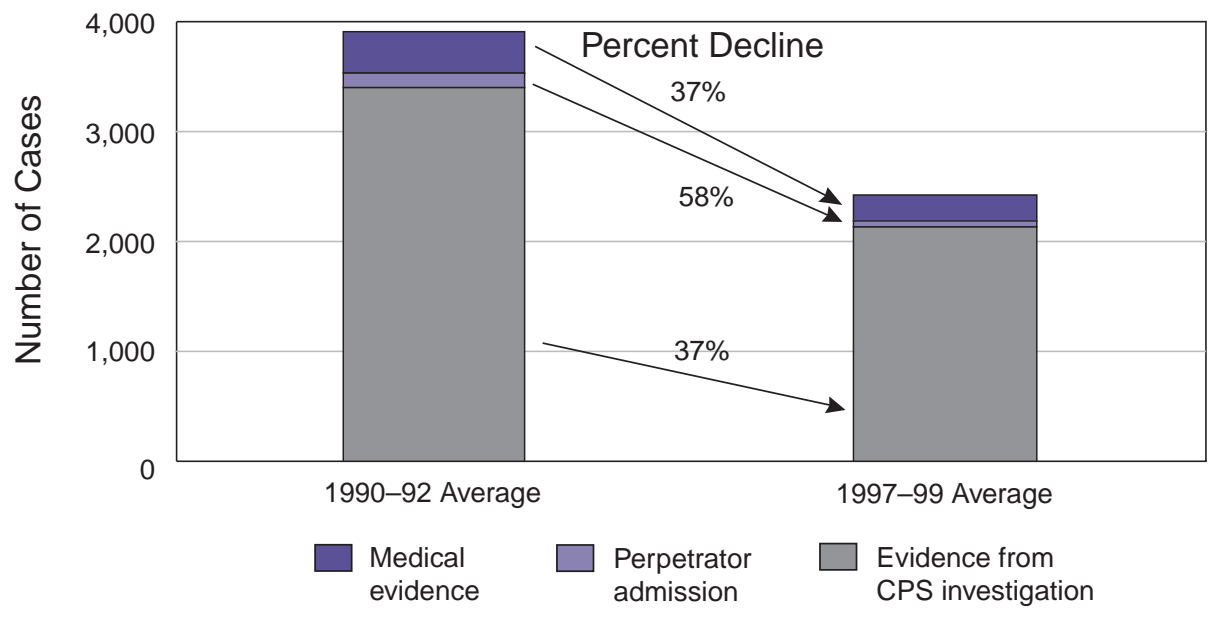

Source: Authors' analyses of unpublished data provided by the Pennsylvania Office of Children, Youth, and Families.

exact opposite of what the explanation would have predicted (see figure 8).

The same data are relevant to another, related explanation for the decline in sexual abuse cases: namely, that the decline is due to an increase in CPS labeling of sexual abuse cases as neglect or "failure to protect" on the part of the nonperpetrating caretaker. That practice may have developed as CPS agencies more carefully defined their role as ensuring the protection of the child in the home. However, here again, a larger decline would be expected in cases involving nonfamily or more distant perpetrators because a classification of neglect would apply primarily in such cases. CPS workers are not likely to label a case of sexual abuse by a father or stepfather simply as neglect on the part of the mother. The more dramatic decline in parental perpetrators seems to weigh against both the "failure to protect" and the noncaretaker exclusion explanation in the states that were examined. 
Figure 6: Illinois Trends in Sexual Abuse Cases, by Type of Evidence/Allegation

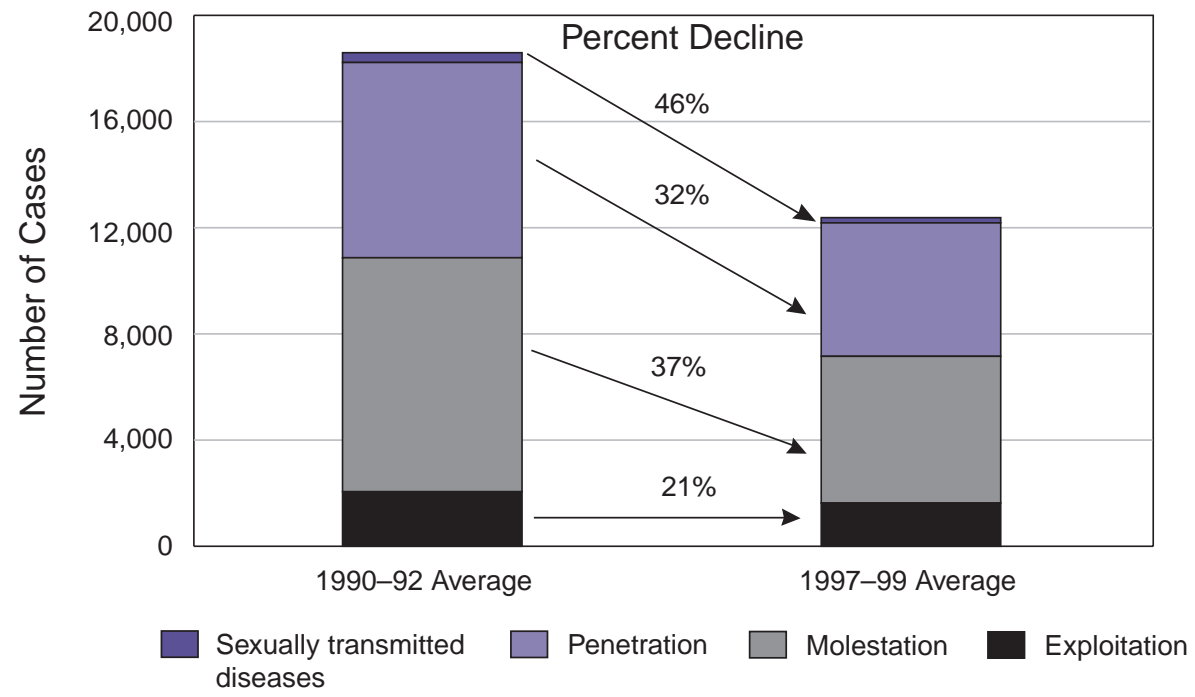

Source: Authors' analyses of unpublished data provided by the Illinois Department of Child and Family Services.

\section{Figure 7: Pennsylvania Trends in Sexual Abuse Cases, by Age of Perpetrator}

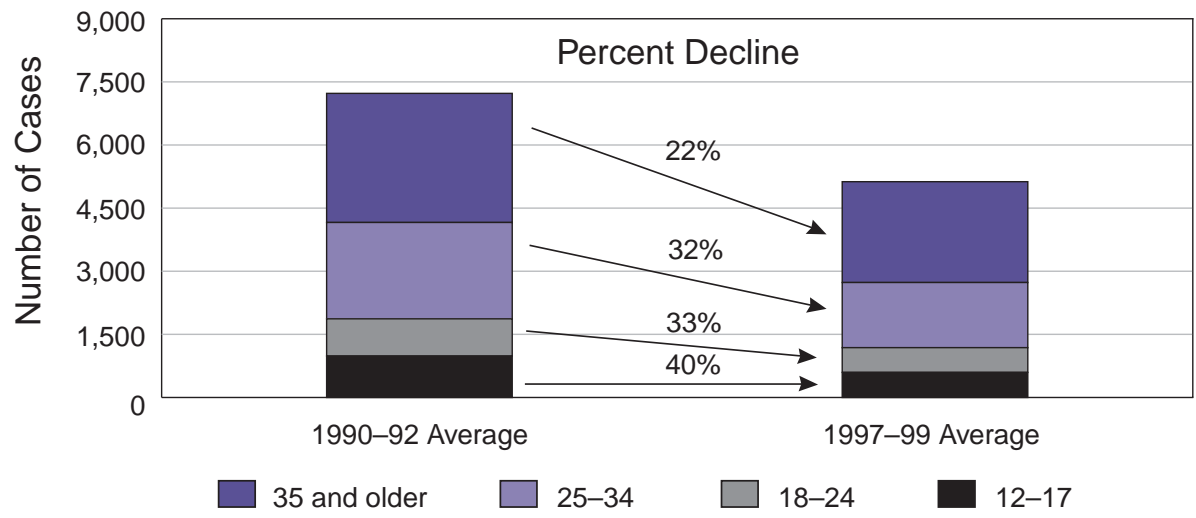

Source: Authors' analyses of unpublished data provided by the Pennsylvania Office of Children, Youth, and Families.

\section{Changes in CPS Data Collection Methods or Definitions}

During the 1990s, a number of state child protection agencies changed the way they define and categorize child maltreatment and how they collect and enter information about the cases that they investigate. In a survey conducted by the authors, many child protection officials felt that these changes were artificially creating what appeared to be a declining trend (Jones, Finkelhor, and Kopiec, 2001). For example, some officials reported that their state had moved from a three-tiered classification system (substantiated/indicated/ unsubstantiated) to a two-tiered system (substantiated/unsubstantiated). Others described changes such as the establishment of central registries and the implementation of more detailed data collection systems as possible causes for the decline. These changes might, in principle, be disruptive to data collection, resulting in artificial declines.

If such changes were behind the decline, state trends could be expected to show a significant decline occurring over a short period of time paralleling the implementation of these changes. An examination of state trends using NCANDS data (see the sidebar on page 3) identified 15 states in which a very large decline (more than 33 percent) in sexual abuse cases occurred in 1 year. When state officials from these "discontinuous decline" states were asked about these trends, more than half were able to explain a change in procedure that could account for the trend. An example of this effect was evident in the CPS data from Oregon, which experienced a 60 -percent decline in substantiated cases (see figure 9), but much of the decline occurred between 1993 and 1994. Discussions with Oregon state officials indicated that prior to 1994, a determination about whether abuse occurred was made with every report, making reports indistinguishable in the database from face-to-face investigations. This policy was changed in 1994, and the result was a drop in the number of cases that were labeled as investigated and substantiated.

Such changes in data collection procedures or definitions are unlikely, however, to account for the large and gradual declines in child sexual abuse cases that occurred in the majority of states. Furthermore, if changes in definition and data collection procedures were occurring, state trends would be expected to show both increases and decreases in the data. Changes in definition or data collection do not acceptably explain the size and consistency of the national decline.

\section{Less Reporting to CPS Due to a Sexual Abuse Backlash}

Another frequently voiced explanation of the decline in child sexual abuse is that professionals who would report abuse have been intimidated by a "sexual abuse backlash" resulting from negative publicity in the media about false allegations, overzealous reporting, and lawsuits seeking damages against those who make reports. Starting in the mid-1980s, highly publicized cases in Jordan, MN, Wenatchee, WA, and Manhattan Beach, CA, raised questions about whether authorities were unfairly targeting innocent citizens. New organizations, advocates, and legal experts came 


\section{Figure 8: Illinois Trends in Sexual Abuse Cases, by Perpetrator's Relationship to Victim}

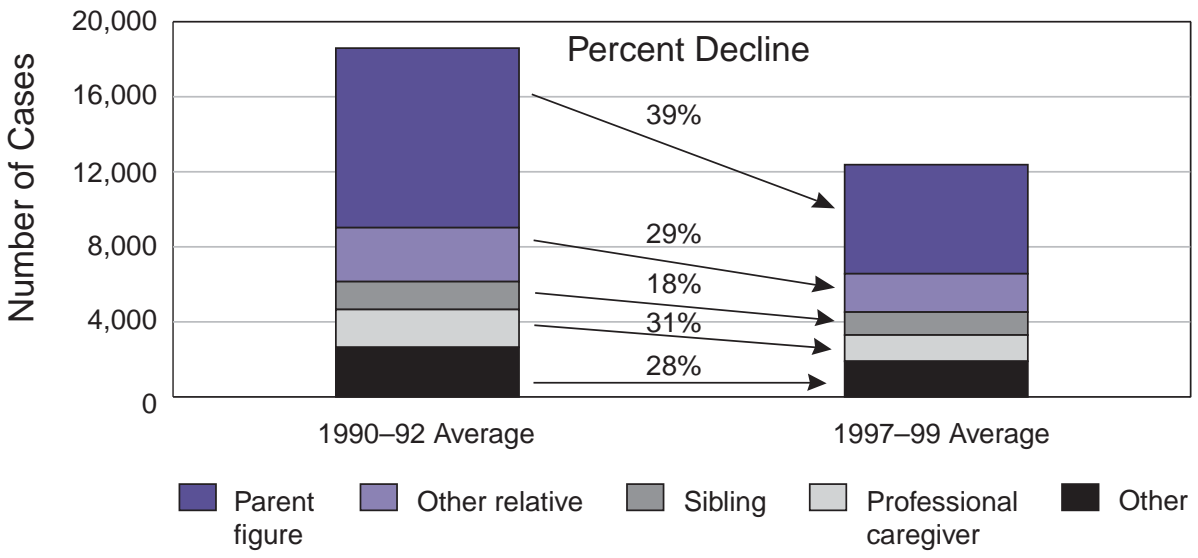

Source: Authors' analyses of unpublished data provided by the Illinois Department of Child and Family Services.

\section{Figure 9: Oregon Trends in Sexual Abuse Reporting and Substantiation, 1989-99}

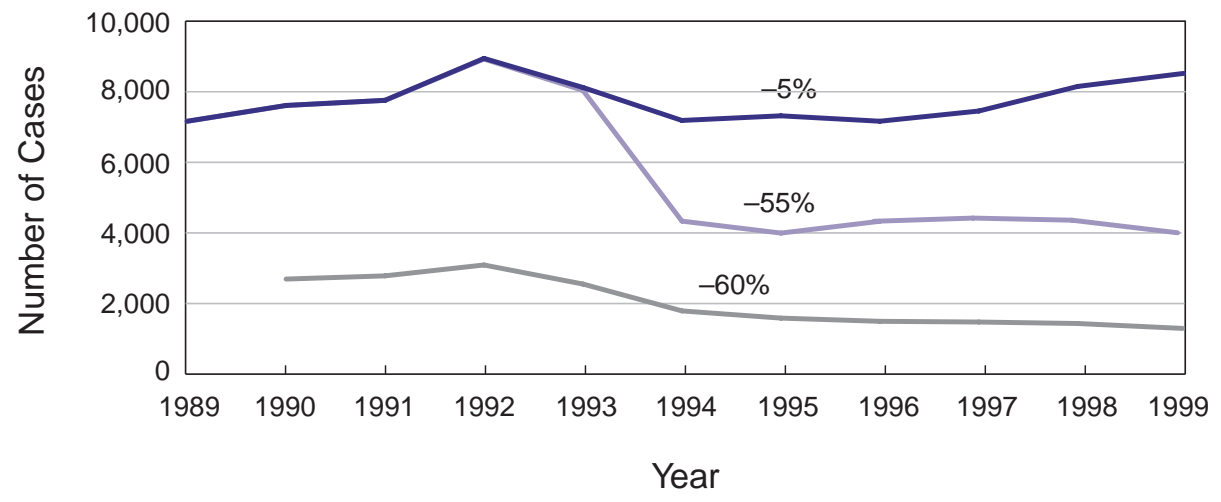

- Reports - Investigated cases - Substantiated cases*

Source: Authors' analyses of unpublished data provided by the Oregon Department of Human Services.

* Data for trends in substantiated cases were drawn from the National Child Abuse and Neglect Data System (NCANDS) annual reports (U.S. Department of Health and Human Services, 1992-2002). together to criticize the criminal justice and child welfare systems' handling of sexual abuse cases (Hechler, 1988). Sources have documented a more negative and critical tone in media coverage of sexual abuse and CPS, which may have dissuaded both laypersons and professionals mandated to report abuse from reporting (Myers, 1994). practice are an example of the latter group. Reporting child abuse has always posed a burden and a risk for physicians because it potentially alienates patients. As independent practitioners, they may also feel particularly vulnerable to damage claims.

The state data that were examined for this Bulletin did not, in any instance, include evidence of a rise in anonymous reporting. In Illinois, however, anonymous reports declined less than the average rate, which could reflect some shift in preference toward anonymous reporting, but within the overall context of a decline in reports from virtually all sources (see figure 10). This pattern is not shared by Pennsylvania, where anonymous reports declined more, not less, than the average rate.

The pattern of reporting by physicians in private practice is also mixed. In Illinois, reports emanating from such physicians declined much more dramatically than average (see figure 11). Their reports did not, however, decline much more than reports from hospital-based physicians, who presumably are more insulated from both economic and legal retaliation by families about whom reports are made. In contrast to Illinois, the decline in Pennsylvania reports from physicians in private practice was dramatically less than the average and less than the decline in reports from hospital-based physicians, the opposite of what the backlash explanation might predict.

Thus, in Illinois, the evidence is somewhat consistent with the backlash or intimidation explanation, although there was a slower decline and not a true rise in anonymous reports. In Pennsylvania, neither anonymous reports nor reports from physicians in private practice show evidence of a backlash. Unfortunately, however, because the backlash explanation concerns attitudes and practices among reporters, it is harder to evaluate with CPS data alone, and the data reported here permit only a weak evaluation of the backlash explanation.

\section{A Diminishing Reservoir of Older Cases}

Another possible explanation for the decline could involve what might be described as the depletion of the reservoir of older, but previously undisclosed, cases with no true decline in the number of new cases. The increasing awareness of sexual abuse in the 1980s may have created an ceptible to retaliation, legal action, or economic boycott. Physicians in private
A backlash or some other intimidation facchild sexual abuse in two ways: more reports might be made anonymously, allowing reporters to seek protection for a child while insulating themselves from criticism might be greatest among those most susor legal action, and the decline in reports 
artificial surge in the number of cases by flushing into view a large number of older or ongoing cases that had previously escaped detection. Only after the reservoir of old cases was depleted would new disclosures of sexual abuse truly reflect new cases. That is, the influx and subsequent depletion of old cases would cause sexual abuse rates to decline without any true decline in actual incidence levels.

If reservoir depletion is responsible for a considerable amount of the decline in child sexual abuse, then the number of cases involving older children should also show a decline. The victims in older, ongoing, and previously undisclosed cases would almost certainly be older at the time of disclosure because they would have been abused for a longer period. Figure 4, which shows trends by age of victim, demonstrates no differential decline for older victims (see page 5). Thus, there is no evidence for the reservoir depletion hypothesis.

\section{A Real Decline in the Incidence of Sexual Abuse}

If the decline in child sexual abuse cannot be fully explained by the hypotheses considered above, then is the decline real?

\section{Figure 10: Trends in Anonymous Reports of Sexual Abuse in Illinois and Pennsylvania, 1991-98}

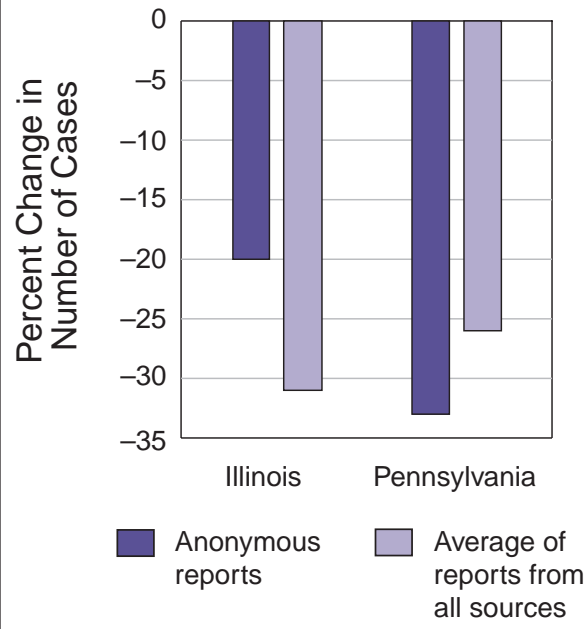

Source: Authors' analyses of unpublished data provided by the Illinois Department of Child and Family Services and the Pennsylvania Office of Children, Youth, and Families. The comparison is between the 1990-92 average and the 1997-99 average.
There are several predictions that would be consistent with a true reduction in the number of children and youth being sexually abused:

$\checkmark$ Decline in the number of self-reports of sexual abuse by victims.

- Decline in related social problems.

- Greater decline in the most readily preventable cases.

- Increase in the incarceration of offenders.

Decline in the number of self-reports of sexual abuse by victims. Unfortunately, sexual abuse is not a crime category tracked by the nation's most reliable measure of self-reported crime victimization, the National Crime Victimization Survey. However, NCVS does ask about rape and sexual assault for victims ages 12 and older, and these crimes include acts counted within the broader definition of child sexual abuse. The NCVS data show that sex offenses against juveniles (ages 12-17) declined 56 percent between 1993 and 2000 , with virtually all the decline occurring in offenses committed by known (family and acquaintance) perpetrators (down 72 percent, see figure 12). Cases involving known perpetrators are the type most likely to be categorized as sexual abuse. The timing and magnitude of this decline in self-reports are parallel to the trend in CPS data on sexual abuse.

Another source of self-report information on sexual abuse comes from the Minnesota Student Survey (see the sidebar on page 3).
The survey includes two questions about experiences with sexual abuse. For sexual abuse by both family and nonfamily perpetrators, these data show a slight rise between 1989 and 1992 and a 22-percent drop from 1992 to 2001 (see figure 13). This trend also parallels the trend in the CPS data.

Decline in related social problems. If sexual abuse were truly declining, the decrease might be paralleled by drops in indicators of other related social problems. These problems could be considered precursors or outcomes of sexual abuse, or they could be affected by similar causal factors. The period in which the decline in sexual abuse occurred also saw declines in a number of other child welfare problems, including:

- Crime and violent crime.

- Births to teenage mothers.

- Children running away.

$\checkmark$ Children living in poverty.

Teen suicide.

In general, the evidence for these other declines is more reliable than the evidence for the decline in sexual abuse.

The decline in crime and violent crime during the 1990s has been widely publicized. The evidence for that decline is based both on self-reports from NCVS and on police reports. NCVS shows a 46-percent decrease in violent crime from 1994 to 2000 (Rennison, 2001), and a 21-percent decrease in intimate partner assault from 1993 to 1998 (Rennison and

\section{Figure 11: Trends in Sexual Abuse Cases Reported by Private and Hospital Physicians for Illinois and Pennsylvania, 1991-98}

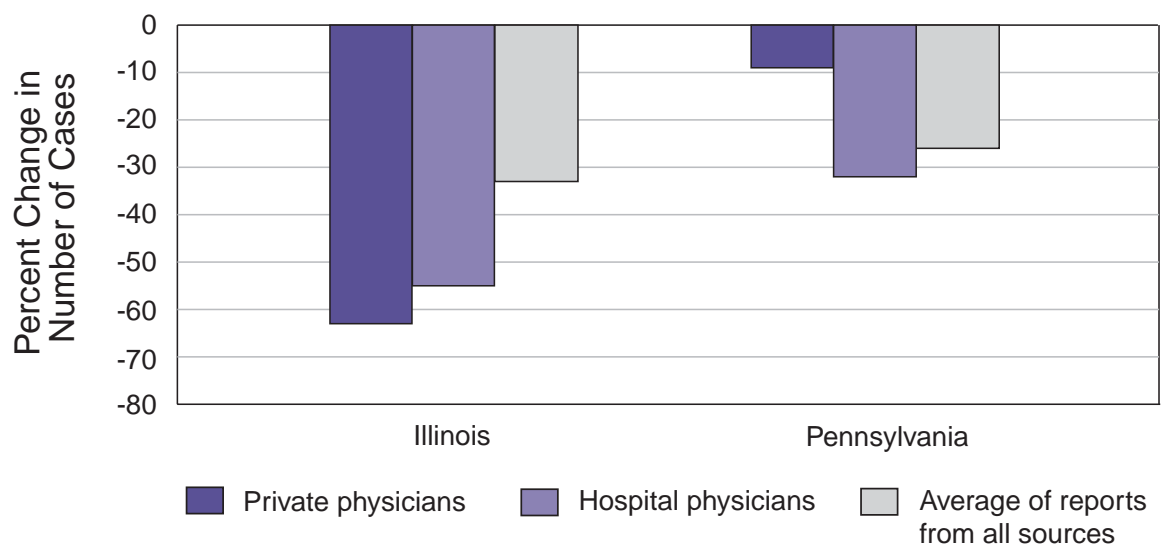

Source: Authors' analyses of unpublished data provided by the Illinois Department of Child and Family Services and the Pennsylvania Office of Children, Youth, and Families. The comparison is between the 1990-92 average and the 1997-99 average. 
Welchans, 2000). The decline in intimate partner assault is particularly noteworthy because of its connections to sexual abuse. Child sexual abuse is thought to be more common in families where there is intimate partner violence (Rumm et al., 2000). Like child sexual abuse, intimate partner violence has in recent years been the subject of substantial publicity, increasingly aggressive efforts at case detection, upgraded law enforcement activity, and stiffened legal sanctions.

Another social problem that has declined markedly over the same period is the number of out-of-wedlock teenage pregnancies. The rate of live births to teenage mothers dropped 28 percent from a high of 39 live births per 1,000 females ages 15-17 in 1991 to 28 per 1,000 in 2000 (Moore et al., 2001). Teen pregnancy has often been an outcome of sexual abuse, both in the form of conceptions resulting from abuse (Boyer and Fine, 1992) and in conceptions resulting from the sexualized behaviors that victims sometime manifest in the wake of abuse (Butler and Burton, 1990). The number of teens who reported being currently sexually active or ever having sexual intercourse also fell during the 1990s (Terry and Manlove, 2000).

Yet another related indicator that experienced a decline is the frequency of children running away. Police reported 28 percent fewer incidents of taking children into custody for running away in 1999 than in 1995 (Federal Bureau of Investigation, 2001). A comparison of data from the Second National Incidence Studies of Missing, Abducted, Runaway, and Thrownaway Children (NISMART-2) with data from NISMART-1 also indicates a decline in the runaway problem between 1988 and 1999 (Hammer, Finkelhor, and Sedlak, 2002). Running away is frequently cited as a coping strategy used by children who are being sexually abused at home, and it is a behavior that also increases a youth's risk for sexual assault and exploitation (Famularo et al., 1990). The decline in running away is consistent with a decline in sexual abuse. Also consistent with a decline in sexual abuse is a drop in teen suicide. Vital statistics show a modest 18-percent reduction in suicide among 15- to 19-yearolds between 1990 and 1999 (Annie E. Casey Foundation, 2002).

In the same period, the percentage of children living in poverty dropped 27 percent, from 22 percent of children younger than 18 in 1992 to 16 percent of children younger than 18 in 1999 (Federal

Figure 12: Trends in Sexual Assaults Against Juveniles, 1993-2000

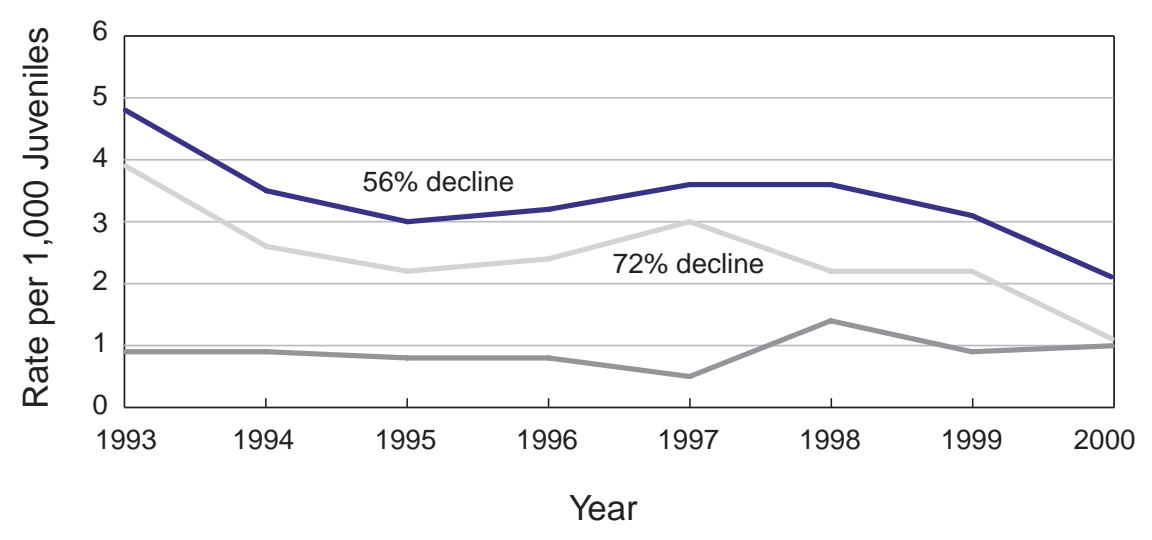

- All offenders $\quad$ Known offenders $\quad-$ Unknown offenders

Note: Juvenile victims are ages 12-17. Known offenders are family members or acquaintances, and unknown offenders are strangers or unidentified.

Source: NCVS, each year, for number of incidents; authors' analyses.

\section{Figure 13: Juvenile Sexual Abuse Trends in Minnesota, 1998-2001}

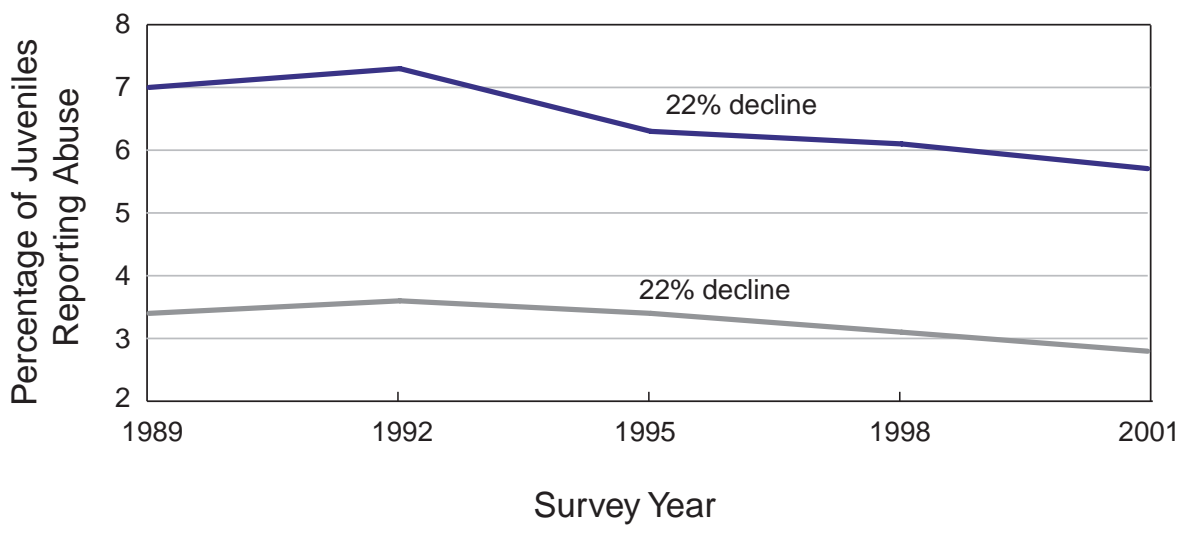

— Nonfamily adult offender _ - Family offender

Note: Respondents are 6th, 9th, and 12th grade students enrolled in public schools in selected Minnesota school districts.

Source: Unpublished data from the Minnesota School Survey.

Interagency Forum on Child and Family Statistics, 2000). This decline was accompanied by a decrease in unemployment and a reduction of families on welfare. Poverty, unemployment, and welfare have generally been viewed more as risk factors for forms of child maltreatment other than sexual abuse. It is possible, however, that increased employment, particularly among potential offenders, may have reduced both opportunities to molest and some of the motivations (such as discouragement and anxiety) behind offending.

Divorce rates also declined over the same time period as the social indicators described above. Divorce rates fell from 4.8 per 1,000 individuals in 1992 to 4.1 per 1,000 in 2000, a decline of 15 percent (U.S. Department of Health and Human Services, 2001). Divorce is generally considered both a risk factor for and a result of sexual abuse. 
Greater decline in the most readily preventable cases. Intensive public awareness about child sexual abuse, combined with aggressive efforts at case finding, prosecution, and incarceration, may have had some deterrent effect on potential offenders. They may be increasingly inhibited by fears of detection and prosecution. Deterrence generally has its greatest effect on those offenders with the most potential for self-control, the biggest stake in conformity, and the fewest other pressures to deviate. Based on this logic, a true decline in sexual abuse would be expected to occur differentially among biological fathers in intact families. They tend to be the least compulsive offenders with a lesser tendency to recidivate, the most responsiveness to treatment, and a considerable stake in conformity (Hanson, 2001).

State data confirm a particularly large decline in sexual abuse by biological fathers in intact families. Figures 3 and 8 (see pages 4 and 7 , respectively) show a decrease in sexual abuse by parental figures and in families with two biological or adoptive parents present. This trend could be interpreted as consistent with an argument that deterrence has played a role in a true decline.

Increase in the incarceration of offenders. Among explanations for the general decline in crime during the 1990s, the large increase in the incarceration of offenders has received the most extensive empirical support (Blumstein, 2000; Conklin, 2003). Although detailed data are insufficient to conduct a careful analysis of the possible impact of incarceration on sexual abuse, the overall pattern is certainly consistent with the idea that increased incarceration played a part in a true decline. Surveys of state correctional facilities suggest that between 1991 and 1997, the number of persons incarcerated in state correctional facilities for sex crimes against children increased 39 percent, from 43,500 to 60,700 (Finkelhor and Ormrod, 2001), after more than doubling from 19,900 in 1986. This does not include the many sexual abuse offenders who receive sanctions that do not involve incarceration for a year or more. Compared with people who commit other forms of child maltreatment, people who commit sexual abuse are much more likely to lose access to their victims (as a result of court order or divorce) or to lose their liberty altogether. The incapacitation of offenders alone should be expected to have some effect on the number of new cases.

\section{Conclusion}

No solid and convincing explanation exists for why sexual abuse cases declined in the 1990 s, although it is important to try to find out why a decline occurred. The answer, if it can be determined, is not likely to be a simple one. In all likelihood, multiple factors were involved in the trend. Based on the strength of current evidence, one of those factors was probably a true decline in the occurrence of sexual abuse. Changes in the practices of professionals who report suspected abuse and of the child protective system probably also have played a part, but how large a part is difficult to ascertain.

The evidence for some true decline in incidents of sexual abuse comes from several directions. One is the decline in self-report measures of sexual assault and sexual abuse. The NCVS and the Minnesota Student Survey are both crucial indicators that are independent of the filtering or policies of social agencies. Although validity problems are always present with the self-reporting of sensitive information, there are no strong reasons to think that candor about sexual abuse has declined.

Another strong piece of evidence for a true decline is the improvement in many other indicators of crime, sexual behavior, and family problems over the same period of time. The decline in these areas suggests general movement toward improvement in the well-being of children. An actual decline in the number of sexual abuse cases seems more plausible in the context of such a trend than it would if the other factors had not improved.

More attention has been focused on child sexual abuse during the past two decades than on any other form of child maltreatment. It should not be surprising that its decline would come before and be greater than that of other forms of maltreatment. Prevention and intervention efforts have included school-based prevention education, treatment programs for juvenile and adult offenders, and greatly enhanced resources for criminal justice investigation and prosecution. It is reasonable to think that, given the scale of these efforts, they have had some success in preventing or intervening in sexual abuse.

The relatively inconsistent evidence for other explanations of the decline in the number of sexual abuse cases also supports the possibility of a true decline in sexual abuse. As discussed earlier in this Bulletin, the other explanations do not lack evidence. Indeed, some states clearly have made statistical and administrative changes that have contributed to the decline. There is evidence both that allegations involving very young children have declined more, perhaps because such cases have less credibility, and that cases involving young perpetrators may have declined because they are seen as outside the purview of the child protection system. Evidence from at least one state is consistent with the possibility that some of the decline in substantiated cases of sexual abuse may be due to a backlash against those who report it.

Taken together, however, the evidence for these other explanations seems to exist only in some places or to explain only a small portion of the decline in substantiated cases. The decline has been so widespread geographically and has occurred across so many categories of children, offenders, types of abuse, and types of evidence that a true decline can be considered as at least one part of the overall picture.

Many observers of the decline in the number of substantiated sexual abuse cases, including state officials, have seemed resistant to the possibility that the numbers represent a true decline, preferring almost any other explanation as an alternative. This attitude may stem from a concern that if people believe sexual abuse is waning, their vigilance and concern about the problem and willingness to support funding will disappear. Increasing numbers of cases were part of what mobilized people and resources during the 1980 s, so declining numbers of cases might have the opposite effect.

Although social problems go through a well-recognized issue/attention cycle and some changes have occurred in the media attitude toward sexual abuse, there are reasons to doubt that a true decline in incidence of the current magnitude could, if recognized, result in a massive desertion of interest or funding. For one, the public and professional interest in the issue of sexual abuse has roots that go far beyond the matter of whether it involves 50,000 or 150,000 cases per year, and relate to the now wellestablished role that it plays in discussions of family problems, gender relations, sexuality, and mental health. The high-profile public and professional role this problem has achieved in recent years will not easily change. Second, the other social problems discussed above that also have experienced recent declines do not appear to 
have suffered any social policy desertion as a result. Homicide, crime, and teen pregnancy are all still issues of ongoing serious policy attention, despite their declines, because they remain serious problems even at reduced levels. The declines may, in fact, have spurred policy interest because problems that fester for a long time without improvement in spite of considerable policy attention become frustrating. Policymakers and the public can become discouraged and decide that such problems are beyond immediate solution. Signs of success from social initiatives can provide the public and policymakers with energy and justification for expanded efforts to reinforce what appears to be working. Of course, the factors influencing public interest and policymaking are complex, but there is no strong reason to believe that evidence of a true decline in sexual abuse by itself will have negative effects on the policy environment around the problem.

Because social policy benefits from understanding the factors that result in success, the hypothesis that sexual abuse has declined should be accepted, and identifying the reasons why it has declined should be a priority. It is extremely important that lessons be drawn from a change of this magnitude in a social problem that has been considered so widespread and corrosive to the well-being of children, families, and communities. Several initiatives might be considered to deepen our understanding.

First, more intensive studies need to be undertaken in individual localities where a full inventory of explanations could be considered, with both quantitative and qualitative evidence available. In individual localities, it may be easier to observe how policy and programmatic changes, including prosecution initiatives, treatment resources, and educational programs, may have been sequenced with the onset or acceleration of a decline in sexual abuse. In addition, localities with different trend patterns (steady declines, increases, no change, and fluctuating patterns) should be compared with one another, and it might be useful if such localities were in the same state and were comparable in other ways. Some local studies might center around the case records of investigative agencies that have maintained stable policies, catchment areas, and detailed recordkeeping practices over a long period, from which it might be ascertained more accurately how case characteristics have changed over time.
It would also greatly help the analysis of the current decline and future trends if data systems relating to relevant factors would be expanded, enhanced, and improved (Finkelhor and Wells, 2003). Currently, data on sex crimes against children are artificially divided between the child protective system and the law enforcement system in a way that prohibits a compre-

hensive assessment of trends in the whole problem. Data from state child protection systems are not gathered in ways that are comparable across jurisdictions; therefore, comparisons of the effects of different policy environments are difficult. In the justice area, systematic information is not readily available on the demographics of persons prosecuted, convicted, incarcerated, or treated for sex crimes against children.

In addition, an understanding of the reasons for the decline has been greatly hampered by the failure of communities to evaluate their varied prevention and intervention efforts. More effort should be made prospectively to observe trends and outcomes as communities implement various prosecution, treatment, community, and school-based educational efforts. In this way, a better inventory of the more and less successful strategies could be tracked in conjunction with the relative decline in different locales.

Researchers may not be able to fully answer the question of why this most recent decline has occurred; however, it is important to be better prepared to understand the sources of any continuing or future declines. To what extent do prevention education, increased public awareness, greater prosecution, and incarceration play roles? Answering such questions can help policymakers formulate policies that will extend and accelerate the decline in sexual abuse and, perhaps, in other forms of child maltreatment.

\section{References}

Annie E. Casey Foundation. 2002. Kids Count 2002. Retrieved March 11, 2003, from www.aecf.org/kidscount/kc2002/ pdfs/summary.pdf.

Blumstein, A. 2000. Disaggregating the violence trends. In The Crime Drop in America, edited by A. Blumstein and J. Wallman. Cambridge, England: Cambridge University Press, pp. 13-44.
Boyer, D., and Fine, D. 1992. Sexual abuse in adolescent pregnancy and maltreatment. Family Planning Perspectives 24(1).

Butler, J.R., and Burton, L.M. 1990. Rethinking teenage childbearing: Is sexual abuse a missing link? Family Relations 39:73-80.

Centers for Disease Control and Prevention. 2000. Tracking the Hidden Epidemics: Trends in STDs in the United States. Atlanta, GA: Centers for Disease Control and Prevention.

Conklin, J.E. 2003. Why Crime Rates Fell. Boston, MA: Allyn and Bacon.

Famularo, R., Kinscherff, R., Fenton, T. and Bolduc, S.M. 1990. Child maltreatment histories among runaway and delinquent children. Clinical Pediatrics 29(12):713-718.

Federal Bureau of Investigation. 2001. Crime in the United States, 1999: Uniform Crime Reports. Washington, DC: U.S. Department of Justice.

Federal Interagency Forum on Child and Family Statistics. 2000. America's Children: Key National Indicators of Well-Being, 2000. Washington, DC: U.S. Government Printing Office.

Finkelhor, D., and Ormrod, R.K. 2001. Offenders Incarcerated for Crimes Against Juveniles. Bulletin. Washington, DC: U.S. Department of Justice, Office of Justice Programs, Office of Juvenile Justice and Delinquency Prevention.

Finkelhor, D., and Wells, M. 2003. Improving national data systems about juvenile victimization. Child Abuse \& Neglect 27(1):77-102.

Hammer, H., Finkelhor, D., and Sedlak, A.J. 2002. Runaway/Thrownaway Children: $\mathrm{Na}$ tional Estimates and Characteristics. Bulletin. Washington, DC: U.S. Department of Justice, Office of Justice Programs, Office of Juvenile Justice and Delinquency Prevention.

Hanson, R.K. 2001. Age and Sexual Recidivism: A Comparison of Rapists and Child Molesters. Ottawa, Ontario, Canada: Solicitor General of Canada.

Harrison, P.A., Fulkerson, J.A., and Beebe, T.J. 1997. Multiple substance use among adolescent physical and sexual abuse victims. Child Abuse \& Neglect 21(6):529-539.

Hechler, D. 1988. The Battle and the Backlash: The Child Sexual Abuse War. Lexington, MA: D.C. Heath. 
Washington, DC 20531

Official Business

Penalty for Private Use $\$ 300$

Jones, L., and Finkelhor, D. 2001. The Decline in Child Sexual Abuse Cases. Bulletin. Washington, DC: U.S. Department of Justice, Office of Justice Programs, Office of Juvenile Justice and Delinquency Prevention.

Jones, L.M., Finkelhor, D., and Kopiec, K. 2001. Why is sexual abuse declining? A survey of state child protection administrators. Child Abuse \& Neglect 25(9): 1139-1158.

Minnesota Department of Children, Families \& Learning, Minnesota Department of Human Services. 2001. Minnesota Student Survey: Key Trends Through 2001. Roseville, MN: Minnesota Department of Children, Families \& Learning.

Moore, K.A., Manlove, J., Terry-Humen, E., Williams, S., Papillo, A.R., and Scarpa, J. 2001. CTS Facts at a Glance. Washington, DC: Child Trends.

Myers, J.B. 1994. The Backlash: Child Protection Under Fire. Thousand Oaks, CA: Sage Publications, Inc.

Peddle, N., and Wang, C.T. 2001. Current Trends in Child Abuse Prevention, Reporting, and Fatalities: The 1999 Fifty State Survey. Working Paper. Chicago, IL: Prevent Child Abuse America.

Rennison, C.M. 2001. Criminal Victimization 2000: Changes 1999-2000 With Trends 1993-2000. Bulletin. Washington, DC: U.S. Department of Justice, Office of Justice Programs, Bureau of Justice Statistics.
Rennison, C.M., and Welchans, S. 2000. Intimate Partner Violence. Special Report. Washington, DC: U.S. Department of Justice, Office of Justice Programs, Bureau of Justice Statistics.

Rumm, P.D., Cummings, P., Kraus, M.R., Bell, M.A., and Rivara, F.P. 2000. Identified spouse abuse as a risk factor for child abuse. Child Abuse \& Neglect 24(11): 1375-1381.

Terry, E., and Manlove, J. 2000. Trends in Sexual Activity and Contraceptive Use Among Teens. Research Brief. Washington, DC: Child Trends.

U.S. Department of Health and Human Services. 2001. National Vital Statistics Report: Annual Summary of Births, Marriages, Divorces and Deaths: United States, 1992 49(6). Washington, DC: U.S. Government Printing Office.

U.S. Department of Health and Human Services, Office of Child Abuse and Neglect. 1992-2002. Child Maltreatment 1990-2000: Reports from the States to the National Child Abuse and Neglect Data System. Washington, DC: U.S. Government Printing Office.

This Bulletin was prepared under grant number 98-JN-PX-0012 from the Office of Juvenile Justice and Delinquency Prevention, U.S. Department of Justice.

Points of view or opinions expressed in this document are those of the authors and do not necessarily represent the official position or policies of OJJDP or the U.S. Department of Justice.
The Office of Juvenile Justice and Delinquency Prevention is a component of the Office of Justice Programs, which also includes the Bureau of Justice Assistance, the Bureau of Justice Statistics, the National Institute of Justice, and the Office for Victims of Crime.

\section{Acknowledgments}

This Bulletin was written by David Finkelhor, Ph.D., Professor of Sociology, and Director, Crimes against Children Research Center, University of New Hampshire; and Lisa M. Jones, Ph.D., Research Assistant Professor of Psychology, Crimes against Children Research Center. For more information on this research, contact the authors at 603-862-1888, david. finkelhor@unh.edu, or Imjones@unh. edu, or visit the Center's Web site at www.unh.edu/ccrc.

The authors would like to thank staff from the following departments for their permission and assistance in obtaining data used in this report: the Pennsylvania Office of Children, Youth, and Families; the Illinois Department of Child and Family Services; the Oregon Department of Human Services; the Minnesota Department of Human Services, Children's Research, Planning and Evaluation Department; and the Minnesota Department of Children, Families \& Learning. 